\title{
Broad spectrum probiotic (Sakhabactisubtil) recovered from Yakutia permafrost soil
}

\author{
Mikhail Petrovich Neustroev*, Nadejda Petrovna Tarabukina, Marfa Pavlovna Fedorova, \\ Svetlana Ivanovna Parnikova \\ Yakut State Research Institute of Agriculture, Yakut, Russia \\ * Corresponding author email : yniicx@mail.ru \\ Published online at www. veterinaryworld.org on 25-03-2011
}

\begin{abstract}
Probiotic "Sakhabactisubtil" has been developed, it has unique biological properties: frank antagonistic effect against pathogen and opportunistic microorganisms (bacteria, fungi and viruses), interferon-evoke activity, immune system enhancing effect, producing a range of ferments, beneficial microflora formation's stimulation, resistance to a number of antibiotics.
\end{abstract}

Keywords: probiotic, Bacillus subtilis bacteria strains, biological activity, diseases prevention and treatment, agricultural animals, silage packing, glacier sanitation.

\section{Introduction}

At present the world community gives a great consideration to food products' safety. In the EU from January of 2006 the application of antibiotics has been banned in animal breeding. Therefore last decades there undergo development and innovation of safe and effective probiotics as alternatives to antibiotics in the whole world including Russia.

Development and application of ecologically friendly biopreparations which favor to animal health, especially in harsh conditions of the Extreme North, is a topical issue in veterinary medicine. Spore-forming bacteria play a special place in a range of probiotics. Probiotics' safety in producing is a reason to study them as a preventive and treatment preparations during different pathologic processes in humans and animals (B.R. Tarakanov, 1987; P.I. Jdanov, 1997; I.I.Bratukhin, I.N. Jirkov, 1999).

In the recent decades the Yakut Scientific Research Institute of Agriculture has developed a range of innovative probiotic preparations on the basis of biologically active and unique local natural strains of bacteria Bacillus subtilis as "Sakhabactisubtil" (approved by the Federal Service for Veterinary and Phytosanitary Surveillance of the Ministry of Agricultural Sciences of the Russian Federation, 14.11.2006). Bacillus subtilis strains "TNP-3" and "TNP-5", recovered from permafrost soil, have been certified and deposited to the All-Russian microorganisms' collection used in animal breeding and veterinary as having frank biological active properties.

Biological properties of preparation "Sakhaba- ctisubtil" based on the strains of bacteria Bacillus subtilis "TNP-3" and "TNP-5":

- frank antagonistic action against many pathogen and opportunistic microorganisms (streptococci, staphylococci, E.coli, salmonella, brucella, campylobacter, atypical mycobacteria and viruses) as well as some of toxigenic fungi (Penicillum, Aspergillus, Stachybotrus) and soil microorganisms pathogens of fungal diseases (Rhizoctonia-solani, Streptomyces, Fusarium oxysporum);

- stimulation of beneficial intestinal microflora development;

- complex of enzymatic activities (proteolytic, gelatinase, amylase, cellulose, $\beta$-gluconase and marked xylanase and fructoziltransferase), which intensify antagonistic action and favor to more frank probiotic effect;

- $\quad$ resistance to a wide range of antibiotics, as a result of it there is a possibility of application in combination with antibiotics and the preparation is also recommended after serious illnesses, antibiotic treatment, with rapidly eliminated dysbacteriosis intestine.

Moreover, the preparation is active inducers of endogenous interferon and enhances immunological reactivity. It adjusts metabolism, improves feed digestion and assimilation and contributes to body weight growing.

Prevention and treatment of newborn calves' and piglets' dysbacterioses

The application of preparation favors to regular 
intestinal microflora formation, except it amounts of bifidus bacteria, lactic acid bacteria and spore-forming bacteria are multiplied, content of lastose-negative microflora is considerably reduced, indices of natural organism resistance are increased (increasing of blood serum bactericidal, lysozyme activities, range of globulin fraction, blood phagocytic activity), sickness rate is reduced, losses out of diarrhea are prevented.

In the prevention of dysbacterioses newborns are draughted orally $10 \mathrm{ml}$ (1 dose) once a day for 3 consecutive days after their birth.

With the purpose of treatment the preparation is prescribed in $10 \mathrm{ml} 3$ times a day until the disapparance of clinical signs of disease. If necessary, "Sakhabactisubtil" can be given in combination with other medicines (antibiotics, sulphonamide, etc.). The same dose of preparation is prescribed for immunity enhancement once a day for 10 consecutive days. Preparation "Sakhabactisubtil" has no side effects on animals, even in the case of overdosing. Preventive use of the preparation protects newborn animals from diseases and its rate is $96-100 \%$ and preservation is $98,5-100 \%$. Beneficial effects of the preparation is $81,8-100 \%$. Rate of diarrhea incidents decreases, rate of death reduces, immunity and resistance to intestinal diseases increase, body weight gaining of newborn animals is significantly improved.

\section{Prevention and treatment of herd horses' respiratory diseases}

"Sakhabactisubtil" can be applied in treatment of horses. The doses of preparation can be injected to a nasal cavity by a draught of $5 \mathrm{ml}$ doubly in 10-12 days. Preparation "Sakhabactisubtil" has a detrimental effect on the causative agent-Streptococcus equi. "Sakhabactisubtil" improves immunity that has a frank therapeutic effect and it shortens recovery.

\section{Prevention of cows' postpartum complications}

The preparation can be used in immunity improvement of cows in calf and correction of vaginal microbiocenosis.

Preparation "Sakhabactisubtil (50 billion CFU) can be used with forage to $5 \mathrm{~g}$ during 10 days 3 consecutive months; The culture liquid of bacteria Bacillus subtilis strains "TNP-3" is injected hypodermically at a dose of $2 \mathrm{ml}$ once in 10 days 3 times a month; The preparation "Sakhabactisubtil" is injected intravaginally after a birth at a dose of $10 \mathrm{ml}$ ( 50 billion CFU) daily for 3 days.

Genital organs' microbiocenosis correction of cows with probiotic preparations normalizes microflora and restores a reproductive ability. It preserves cow healthy, and it in turn contributes to producing environmentally safe livestock.

\section{Prevention of animals' mycotoxicosis}

"Sakhabactisubtil" can be used in feed to prevent fungal toxins. Can be Fed with fodder infected by molds also. Cattle are treated with the preparation at a dose of 50 billion CFU per 1 head orally once a day during 30 days.

The preparation has a frank antagonistic activity against toxigenic mold (Penicillium, Aspergillus and Stachybotrus). It improves an immunological reactivity of organism and normalizes intestinal microbiocenosis.

\section{Prevention of metabolic disorders in cattle}

Mineral and vitamin supplement containing "Sakhabactisubtil" with a frank enzymatic activity is used in prevention of methabolism.

It can be used daily at a dose of 50 billion CFU during the last 2 months of pregnancy. Mineral and vitamin supplement with preparation "Sakhabactisubtil" provides a daily requirement of vital micronutrients, vitamins, and stimulates physiological and biochemical processes in the body. Moreover, it increases a digestibility of nutrients' intake by available enzymes and increases productivity. The application of mineral and vitamin supplement with preparation "Sakhabactisubtil" improves immunity and enhances enzyme activity. It stimulates biochemical processes and normalizes intestinal microflora. Thereby it contributes to the prevention of metabolic disorders and improves productivity.

\section{Sanitation of ice-houses of fur animals' fodder storing}

Preparation "Sakhabactisubtil" can be used for the sanitation of ice-houses at a dose of 1 billion $\mathrm{CFU} / \mathrm{ml}$ at $100 \mathrm{ml} / \mathrm{m}^{2}$. Solution of the preparation is applied by fogging.

The biological method of ice-houses' sanitation using preparation "Sakhabactisubtil" has showed high efficacy against mold. The application of preparation restrains the development of toxigenic fungi and Aspergillus, Mucor mold in ice-houses up to 3 months.

\section{Preservation of silage by addition of a microbial preparation}

Preparation "Sakhabactisubtil" can be added to preserve silage at a rate of $100 \mathrm{ml}$ containing 1 billion 
$\mathrm{CFU} / \mathrm{ml}$ per $1000 \mathrm{~kg}$ of silage. The preparation has not only antagonistic property against many pathogens, but also a complex of enzymatic activities (proteolytic, gelatinase, amylase, cellulose, $\beta$ gluconase, xylanase, fructoziltransferase).

Addition of the preparation to silage disinfects feed from pathogenic and opportunistic microorganisms and it catalyzes the enzymatic processes and provides high quality of succulent feed safety.

Thereby a wide range of preparation biological activities defines its many-sided application in agriculture and its prospects in medical application.

Preparation "Sakhabactisubtil" which is developed on the basis of Bacillus subtilis bacteria "TNP-3" and "TNP-5" as a component of mineral and vitamin supplements, premixes and combined feed is an effective in prevention and treatment of diseases of respiratory apparatus, digestion, reproduction, mycotoxicosis, in microbiocenosis correction, immunobiological organism reactivity of animals. The preparation is perspective in feed production (haylage and silage). It is widely used in republic animal breeding and certified in farms of Novosibirsk and Amur regions, Republic of Buryatia, Mongolia. Prophylactic efficiency is $90-100 \%$. Economic efficiency is $16-17$ roubles for 1 rouble.

Scientific novelty of the development is protected by 12 patents of the Russian Federation. The production is certified and organized under microbial preparations' development laboratory of the Yakut Scientific Research Institute of Agriculture.

\section{References}

1. Bratukhin I.I., Jirkov I.N. Application of probiotic RAS for correction of dysbacteriosis in calf // Veterinary, 1999, №4., p. 40-42. (in Russian).

2. Jdanov P.I. Biological and epizootic aspects of production and application of new probiotic from bacteria Bacillus: abstract. Saint-Petersburg, 1997, p. 8-20. (in Russian).

3. Neustroev M.P., Tarabukina N.P., Bylgaeva A.A. The ways of cattle mycotoxicosis prevention with the application of preparation "Sakhabactisubtil" in conditions of Yakutia: guideline / the Russian Agricultural Academy, the Yakut State Scientific Research Institute. - Yakutsk, 2010. $-2^{\text {nd }}$ edition, revised and corrected. - p. 16. (in Russian).

4. Tarabukina N.P., Neustroev M.P., Fedorova M.P., Shadrina Ya. L., Maksimova A.N. Gastrointestinal disturbance prevention in cage animal breeding; guideline / the Russian Agricultural Academy, the Yakut State Scientific Research Institute. - Yakutsk, 2008. - p. 12. (in Russian).

5. Tarabukina N.P., Neustroev M.P., Parnikova S.I., Fedorova M.P. "Sakhabactisubtil" probiotic application in newborn piglets' and calves' diarrhea prevention and treatment: guideline / the Russian Agricultural Academy, the Yakut State Scientific Research Institute. - Yakutsk, 2003. - p. 16. (in Russian).

6. Tarakanov B.V. the use of microbial preparations and products of microbiological synthesis in animal breeding. M.: VNIITEI agroprom, 1987. - p. 18-35. (in Russian).

7. Tatarinova S.S., Neustroev M.P. "Sakhabactisubtil" preparation application to incalver / Zootechniya. - 2006. No.12. - p. 21-23. (in Russian). 